\title{
Elgetako farmazian II motako Diabetes Mellitusa (DM2) pairatzeko arriskua izango duten herritarrak antzemateko programa pilotua
}

\author{
Detection of patients at risk of developing type-2 diabetes in a community \\ pharmacy of Elgeta \\ Ane Azpiazu ${ }^{1,3,}$ Ainhoa Oñatibia-Astibia ${ }^{2}$, Amaia Garitano ${ }^{1}$, Elena Elkoro ${ }^{1}$, Nerea Osinalde ${ }^{3}$ \\ ${ }^{1}$ Elena Elkoro farmazia, Elgeta, Gipuzkoa \\ ${ }^{2}$ Gipuzkoako sendagaigileen elkartea \\ ${ }^{3}$ Biokimika eta Biologia Molekularra Saila, Farmazia Fakultatea, UPV/EHU \\ ainhoaonatibia@redfarma.org
}

\section{Laburpena}

II motako Diabetes Mellitusa (DM2) Espainiako hirugarren gaixotasun kroniko nagusia da. Gaixotasunak duen prebalentziagatik eta horren prebentzioaren garrantziagatik, Gipuzkoako farmazietan "DM2a Pairatzeko Arriskua Antzemateko Programa" jarri da martxan 2017ko urtarrilean. Helburua, Elgetako botikan, programan parte hartzen duten gizabanakoek DM2a pairatzeko duten arriskua kalkulatzea eta Elgetako biztanleriaren osasun-egoera aztertzea da. Horrez gain, komunitateko farmaziak DM2a pairatzeko arriskuaren detekzioa komunitateko zerbitzu farmazeutiko bezala bultzatzea du helburu. Programak 6 hilabeteko iraupena izan du eta ikerketa prospektiboa izan da. Gaixotasuna pairatzeko arriskua kalkulatzeko Findrisk testa erabili da eta osasun-egoeraren ikuspegi orokorragoa lortzeko pazienteei presio arteriala neurtu zaie. Arestian aipatutako programan, Elgetako botikan, 58 pertsonak hartu dute parte. Horietatik, 10 urtetan DM2a pairatzeko arrisku baxukoak 7 pertsona $(\% 12,1)$, ertainekoak $36(\% 62,1)$ eta altukoak 15 izan dira $(\% 25,8)$. Hipertentsioarentzako medikamentua hartzen ez zuten 37 pertsonetatik $15(\% 40,5)$, pre-hipertentso edo hipertentso bezala sailkatu dira. Hipertentsioaren kontrako medikamentua hartzen zuten 21 pertsonetatik $12(\% 57,1)$ ez daude kontrolpean. Lortutako emaitzek Elgetako biztanleriaren osasun-egoera oro har ona dela erakusten dute. Hala ere, hainbat neurketatan (gerriko perimetroa, eguneroko ariketa fisikoa eta hipertentsioa), ahuleziak antzeman dira. Hori dela-eta, Elgetako biztanleriaren osasun-heziketa indartu behar dela ondorioztatu da.

Gako-hitzak: Glukosa, II motako diabetes mellitusa, lehen mailako prebentzioa, komunitateko farmazia.

\section{Abstract}

Type-2 Diabetes Mellitus is the third most prevalent chronic disease in Spain. Due to its prevalence and the importance of its prevention, a program called "Detection of patients at risk of developing type 2 diabetes" was initiated in January 2017 in the community pharmacies of Gipuzkoa- The objective of the present study was to calculate the risk of developing diabetes and to establish the health condition of people living in Elgeta (Gipuzkoa). Moreover, the study was designed to encourage the service of detecting the risk of diabetes in the community pharmacy. The program lasted 6 months and consisted of a prospective research. The Findrisk test was used to calculate the 
risk of developing diabetes, whereas the arterial pressure of patients was measured to obtain a more general view of the health situation of the population in Elgeta. 58 people in Elgeta participated in the program. 7 participants (12.1\%) had low risk of developing diabetes in ten years, 36 participants (62.1\%) had medium risk and 15 participants (25.8\%) had high risk. Within the participants who were not taking any antihypertensive medication, 15 of them (40.5\%) were classified as having a prehypertensive or hypertensive condition. Within the participants who were taking antihypertensive medication, 12 participants (57.1\%) did not have their hypertension controlled. This study shows that the health condition of people living in Elgeta is overall acceptable. However, some of the health indicators measured (waist perimeter, daily physical activity and hypertension) reflect points which could be improved. Therefore, we can conclude that the health education of people in Elgeta should be improved.

Keywords: Glucose, Diabetes Mellitus Type 2, primary prevention, community pharmacy.

Bidalia: 2018ko urtarrilaren 18an.http://doi.org/10.26876/osagaiz.1.2018.130

Onartua: 2018ko apirilaren 8an.

\section{Sarrera eta helburuak}

Diabetes mellitusa (DM) gaixotasun metaboliko batzuen multzoa da. Kasuan kasu, intsulinaren jariaketan, jardueran edo bietan akatsak gertatzen dira, eta ondorioz, ohi baino glukosa kantitate handiagoa dago gaixoen odolean (hipergluzemia). Gaixotasuna ez bada modu egokian tratatzen, diabetesak arazo akutu eta kroniko latzak eragiten ditu, eta kasu larrienetan heriotza ere eragin dezake (1).

DM mota ezberdinak daude: (i) I motako diabetesa (DM1): gaixotasun autoimmunea da. Pankrean aurkitzen diren eta intsulina jariatzeaz arduratzen diren Langerhans irletako beta-zelulen suntsiketan datza (2). (ii) II motako diabetesa (DM2): intsulinaren jariaketaren edo/eta intsulinaren eraginaren akatsen ondorioa da eta proteina eta lipidoen asaldura metabolikoen ondorio den hipergluzemia kronikoan datza (3). (iii) Haurdunaldiko diabetesa: glukosarekiko intolerantzian datzan gaixotasuna da; lehenengoz haurdunaldian antzematen dena eta orokorrean erditu ostean desagertzen dena (4). (iv) Diabetes sekundarioa: beste medikamentu, gaixotasun endokrino edo herentziazko gaixotasun baten ondorioz garatzen den diabetes mota da (5).

DM2 XXI. mendeko pandemia da. Espainiako Estatuko hirugarren gaixotasun kroniko nagusia izanik,patologia honek estatuko osasun-gastuaren \% 8,2 (1.770€ paziente/urte) eragiten du (6). Di@betes ikerketaren arabera, Espainiako Estatuan diabetesaren prebalentzia \% 13,8koa da 18 urtetik gorako biztanlerian, eta horietatik ia erdiek ez dakite gaixotasuna pairatzen dutenik. Diabetesaren prebalentzia eta glukosaren erregulazioaren alterazioak nabarmen areagotzen dira adinarekin, gizonetan emakumeetan baino handiagoak izanik. Diabetiko gehienek (>\% 90) II motako diabetesa (DM2) pairatzen dute. DM2a da herrialde garatuetako morbimortalitate goiztiarraren kausa nagusietariko bat; izan ere, arazo mikrobaskularrak (erretinopatia, nefropatia eta neuropatia) eta makrobaskularrak (kardiopatia iskemikoa, istripu zerebrobaskularra eta iskemia arterial periferikoa) eragiten baititu (7). Hori dela-eta, DM2a pairatzeko arrisku-faktoreak (1. taula) zeintzuk diren ezagutzea ezinbestezkoa da, gaixotasuna bera eta diabetesak eragin ditzakeen arazoak saihestu ahal izateko. 


\begin{tabular}{|c|c|}
\hline ALDATU EZIN DAITEZKEEN ARRISKU-FAKTOREAK & ALDATU DAITEZKEEN ARRISKU-FAKTOREAK \\
\hline $\begin{array}{ll}\text { - } & \text { Adina (>45), arraza/etnia. } \\
\text { - } & \text { DM2aren aurrekari zuzenak izatea. } \\
\text { - } & \text { Haurdunaldiko diabetesaren aurrekariak } \\
\text { izatea. } \\
\text { - } \quad \text { Jaiotzean } 4 \mathrm{~kg} \text { baino gehiago izatea. }\end{array}$ & 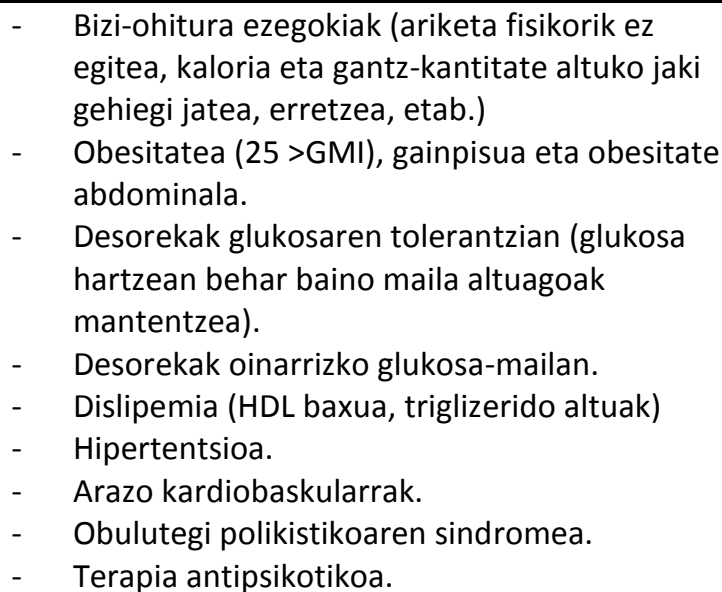 \\
\hline
\end{tabular}

GMI: Gorputz Masaren Indizea $\left(\mathrm{kg} / \mathrm{m}^{2}\right)$; HDL: dentsitate handiko lipoproteina.

1.taula.DM2aren arrisku-faktoreak (8).

DM2a pairatzeko arrisku-faktore asko dauden arren, gaixotasun honetarako aldez aurreko joerak oinarri genetiko indartsua du. DM2a herentzia bidez izateko probabilitatea \%35ekoa da. Gainera, aldakortasun genetiko askok gaixotasuna pairatzeko arriskuan eragiten dutela ezagutzen da gaur egun. Aldakortasun genetiko horiek ingurunearekiko esposizioaren ondorio edo herentzia bidez jasotakoak izan daitezke (9).DM2a pairatzeko arriskuaren detekzioak eta pre-diabetesa duten pertsonen eguneroko bizitzan esku-hartzeak gaixotasunaren hasiera atzeratzen edo murrizten duela ikusi da (10).

Hori guztia dela-eta, lan hau Gipuzkoako sendagileen elkarteak (GSE) martxan jarritako eta Elgetako farmazian garatutako "DM2a Pairatzeko Arriskua Kalkulatzeko Programa"n oinarritu da.

Lan honen helburu nagusia, Elgetako farmaziara gerturatzen ziren gizabanakoetan DM2a pairatzeko zuten arriskua kalkulatzea da. Horrekin batera, DM2a zertan datzan jorratzea eta gaixotasunean eragiten duten arrisku-faktoreak lantzea izan zen itua. Gainera, Elgetako farmazian bildutako datuak aztertu ziren Elgetako biztanleriaren osasun-egoeraren berri izateko. Bestalde, gaixotasunaren prebentzioan farmazialarien esku-hartzea bultzatu nahi izan zen, diabetesaren detekzio goiztiarra edo prebentzioa farmazietan eskainitako zerbitzu farmazeutiko baten bidez.

\section{Materiala eta metodoa}

Gipuzkoako Sendagileen Elkarteak (GSE) Gipuzkoako farmazietan "Il motako Diabetes Mellitusa (DM2) Pairatzeko Arriskua Antzemateko Programa" jarri zuen martxan 2017. urtearen hasieran. Programaren iraupena 6 hilabetekoa izan zen (2017-01/2017-06) eta Gipuzkoako 120 farmaziak hartu zuten parte ikerketa prospektibo multizentriko honetan.

Programa honek, Euskadiko Ikerkuntza Klinikoko Batzorde Etikoaren onespena jaso du gizabanakoekin eta haien datuekin lan egiteko. Horrez gain, GSEko zuzendari teknikoak ikerketako datuak erabiltzeko baimena eman du.

Arestian aipatu bezala, lan hau zehazki Elgetako farmazian gauzatu da. Elgeta 1.137 biztanleko herria da eta nabarmentzekoa da farmazia bakarra dagoela herri osoan. Gainera, Elgeta herri txikia izanik,farmazialariek osasun-zentroan dauden mediku eta erizainarekin harreman estua dute. 
Programa zenbait fasetan garatu da. Lehenik eta behin, Elgetako biztanleriari programaren berri eman zaio. Gero, programan onartuak izan direnei Findrisk testa egin zaie DM2a pairatzeko duten arriskua kalkulatzeko. Horrez gain, programako parte-hartzaileei tentsio arteriala neurtu zaie hipertentsioak (HTA) DM2a pairatzeko arriskuan duen garrantziagatik (1). Lortutako emaitzetan oinarrituta, kasuan kasu interbentzio zehatz bat garatu da. Azkenik, jasotako emaitzak eta egindako interbentzioak erregistratu egin dira.

\subsection{Zerbitzua ezagutarazi}

DM2a antzemateko programa egunkarien, kartelen eta farmazialarion bidez eman zen ezagutzera.

Behin pertsonen arreta lortuta, aurrez zehaztutako irizpideak betetzen zituzten gizabanakoak bakarrik onartu dira programan. Pazienteak 40 urte izatea, edo 25-39 urte tartean arriskufaktoreetako bat izatea (DM2 gaixoak familian, gehiegizko pisua, dieta ez osasuntsua, ariketa fisiko eza edo presio arterial altua). DM2a diagnostikaturik zuten pertsonak, diabetesarentzako medikamentua hartzen zuten pertsonak edo galdeketa burutzeko gai ez ziren pertsonak programatik kanpo gelditu ziren.

Pazienteei programa ezagutarazi zitzaien momentu berean, interesa erakutsi bazuten, galderak egin zitzaizkien goian aipatutako irizpideak betetzen zituzten jakiteko. Irizpideak betetzekotan, zuzenean Findrisk testa egiten zitzaien. Aldiz, irizpideren bat bete ezean, programan parte-hartzea ezinezkoa zutela azaldu zitzaien.

\subsection{Findrisk testa eta tentsio arteriala}

Programan sartzea onartu zuten gizabanakoei 8 galderatan datzan Findrisk testa azaldu eta egin zitzaien botikako banakako arreta eskaintzen den leku pribatuan. Findrisk testeko 8 galderak DM2a pairatzeko arrisku-faktoreekin daude erlazionatuta. Jarraian aipatzen dira zeintzuk diren arriskufaktore horiek:

1. Adina: Ikusi da DM2aren prebalentzia adinarekin batera handitzen dela eta nabarmen egiten duela gora zahartzaroan (11).

Adina: $<45$ urte $=0$ puntu; $45-54$ urte $=2$ puntu; $55-64$ urte $=3$ puntu; $>64$ urte $=4$ puntu.

2. Gorputz Masaren Indizea (GMI): GMI $>25 \mathrm{~kg} / \mathrm{m}^{2}$ den kasuetan, glukosaren intolerantzia eta DM2a pairatzeko arriskua emendatu egiten da adina edozein dela ere, GMI altua izateak intsulinarekiko erresistentzia eragiten baitu. DM2 kasu gehienak (>\% 80) gizentasunaren ondorioz ematen dira eta pisua jaisteak arriskua murrizten du (11). GMI balioa $25-30 \mathrm{~kg} / \mathrm{m}^{2}$ duten gizabanakoek DM2a pairatzeko arrisku ertaina daukate, aldiz, balio horietatik behera gaixotasuna pairatzeko arriskua baxua da (11).

GMI: $<25 \mathrm{~kg} / \mathrm{m}^{2}=0$ puntu; $25-30 \mathrm{~kg} / \mathrm{m}^{2}=1$ puntu; $>30 \mathrm{~kg} / \mathrm{m}^{2}=3$ puntu.

3. Gerriaren perimetroa: Gerriaren perimetroa zentimetro 1 handitzeak DM2a pairatzeko arriskua eta oinarrizko glukosa kontzentrazioen desoreka izateko arriskua \%3,5 eta \%3,2 emendatzen du, hurrenez hurren (11).Arriskua kalkulatzeko erabiltzen diren gerriaren perimetroaren balioak sexuaren arabera ezberdintzen dira. Emakumeetan 80-88 cm tarteko balioek arrisku ertaina adierazten dute. $80 \mathrm{~cm}$-tik behera arriskua baxua da, eta $88 \mathrm{~cm}$-tik gora, berriz, handia. Gizonetan kontuan hartzen diren balioak altuagoak dira emakumeekin konparatuta. Arrisku ertaina adierazten duten balioak $94-102 \mathrm{~cm}$ tartean daudenak dira; 94 
cm-tik behera arriskua baxua da eta 102 cm-tik gora, aldiz, handia. Gerriaren perimetroaren eta GMlaren arriskuen garrantziaren arteko aldea bereizten saiatu diren ikerketek ez dute aurkitu arriskuetako batek besteak baino garrantzi handiagoa duenik DM2a pairatzeko orduan (11).

Gerriko perimetroa:

- Gizonezkoetan: $<94 \mathrm{~cm}=0$ puntu; $94-102 \mathrm{~cm}=3$ puntu; $>102 \mathrm{~cm}=4$ puntu.

- Emakumezkoetan: $<80 \mathrm{~cm}=0$ puntu; $80-88 \mathrm{~cm}=3$ puntu; $>88 \mathrm{~cm}=4$ puntu.

4. Sedentarismoa: Bizitza sedentarioa daukaten pertsonek energia-gastu txikia daukate. Horrek pisua irabaztea eragiten du, eta, ondorioz DM2a pairatzeko arriskua emendatu egiten da. Hainbat ikerketatan, gizabanakoen glukosaren tolerantzia edozein izanda ere, neurrizko ariketa fisikoa eginda DM2 kasu berrien intzidentzia jaitsi egiten dela ikusi da $(11,12)$.

Egunean kirola 30 minutuz egitea $=0$ puntu; egunean kirola 30 minutu ez egitea $=2$ puntu .

5. Fruta eta barazki gutxi jatea: Hipertentsioan, DM2a pairatzeko arrisku-faktoreetako bat duten pertsonetan dosi-erantzun harremana dagoela ikusi da. Fruta eta barazkiak jateak funtzio kardiobaskularraren eta endotelio menpekoa den hodi zabalkuntzaren hobekuntzan hartzen du parte. Gainera, frutak eta barazkiak diabetesaren tratamenduan onuragarriak direla ere ikusi da. Beraz, zenbat eta jaki mota horiek gutxiago jan, diabetesa pairatzeko arrisku handiagoa dago (8).

Egunero fruta eta barazkiak jatea $=0$ puntu; egunero fruta eta barazkiak ez jatea $=1$ puntu.

6. Hipertentsioa: HTA (>140/90mmHg) pairatzen duten pertsonek tentsioa normal dutenek baino 2,5 aldiz arrisku gehiago dute diabetesa izateko (8).

Hipertentsioaren kontrako medikamentuak hartzea $=2$ puntu; hipertentsioaren kontrako medikamentuak ez hartzea $=0$ puntu.

7. Glukosa-maila altuak: Odolean glukosa-maila altuak izatea glukosaren erregulazioaren akats bategatik gertatzen da. Pertsona batek glukosaren erregulazioaren asaldura badu, pre-diabetesa duela esaten da. Egoera horretan glukosa basala eta glukosarekiko tolerantzia asaldatua daude eta hemoglobina glikosilatuaren balioak igo egiten dira; beraz, DM2a pairatzeko arriskua areagotzen da (13).

Noizbait glukosa-maila altuak aurkitu izana = 5 puntu; inoiz glukosa-maila altuak aurkitu ez izana $=0$ puntu.

8. Familia-aurrekariak: Lehen graduko ahaideek eragin handia dute arrisku-faktore bezala. DM2a pairatzen duen ama edo aita duen pertsonak gaixotasuna garatzeko 2 edo 3 aldiz arrisku gehiago du, 5 edo 6 aldiz gehiago gaixotasuna guraso biek pairatzen badute (11).

Familian diabetesa duen pertsonarik ez izatea $=0$ puntu; aitona-amona, lehengusu edo osaba-izebek diabetesa izatea = 3 puntu; guraso, anai-arreba edo seme-alabek diabetesa izatea $=5$ puntu.

Testaz gain, nahiz eta programaren parte ez izan, pazienteei presio arteriala neurtu zitzaien beren baimenarekin. Hori pazienteen egoeren ikuspegi zehatzago bat izateko egin da, hipertentsioak gaixotasun honetan duen garrantzia dela-eta (8). Presio arterial altua daukaten eta tratamendurik gabe dauden pazienteetan tentsioaren segimendua egin zaie. Segimendua programatik kanpoko interbentzioa izanda ere farmaziak pazienteen osasunarengatik egin du. 


\subsection{Farmazialariaren interbentzioa}

Farmazialariak Findrisk testa parte-hartzaileei egin ondoren, partaide bakoitzaren puntuaketaren araberako interbentzioa burutu du:

- $\quad \leq 6$ puntuazioa: pazienteari DM2a pairatzeko arrisku baxua duela esan zaio eta emaitza GSEk farmaziara bidalitako koadernoan jaso da.

- 7-14 puntuazioa (biak barne): pazienteari DM2a pairatzeko arrisku ertaina duela esan eta osasun-heziketa pertsonalizatua diseinatu zitzaion. Hau da, paziente bakoitzaren arabera eta testean emandako erantzunak kontuan hartuta, behar gehien dituen ataletan indarturik eta GSEk emandako triptiko baten laguntzaz heziketa espezifiko bat diseinatu da.

- $\quad \geq 15$ puntuazioa: pazienteari DM2a pairatzeko arrisku altua duela esan zitzaion, osasunheziketa diseinatu zitzaion eta glukosaren proba egiteko baimena eskatu zitzaion. Pazientearen erantzuna baiezkoa izatekotan, beste egun baterako hitzordua eman eta baraurik etortzeko esan zaio. Proba egin baino lehen pazienteak baimen informatua sinatu behar izan du farmazialariak glukosaren neurketa egin ahal izateko. Paziente horietan neurtutako odoleko glukosa-kontzentrazioa $<110 \mathrm{mg} / \mathrm{dl}$ izan bada, neurketa 5 urte barru errepikatzea gomendatu da. Neurketa errepikatzean $110 \mathrm{mg} / \mathrm{dl}-\mathrm{ko}$ balioa gaindituko balu, medikuarengana bideratuko litzateke pazientea eta medikuak hartutako erabakiaren berri farmazialariari emateko eskatuko litzaioke. Lehengo aldian neurketaren balioa $\geq 110 \mathrm{mg} / \mathrm{dl}$ izan bada, pazientea zuzenean medikuarengana deribatzen da gutun baten bidez. Kasu guztietan, Fidrinsk testaren emaitzak eta egindako interbentzioa GSEk farmaziara bidalitako koadernoan jaso dira.

Tentsioa, Findrisk testa egin duten pertsona guztiei egin zitzaien. Odol-tentsioa neurtzeko aparatu elektronikoa erabili zen eta neurketa bi alditan errepikatu zen, lehenengo emaitza zuzena zela baieztatzeko. Pertsonaren batek urduritasuna erakusten bazuen eta emaitzak tentsio altua erakusten bazuen, hurrengo egunean proba berriz egiteko esaten zitzaion. HTArako tratamenduarekin zeuden pertsonetan kontsideratu zen tentsioa kontrolaturik zegoela presioa $<140 / 90 \mathrm{mmHg}$ bazen. HTArako tratamendurik gabeko pertsonetan, berriz, presioa 130-139/85-89 $\mathrm{mmHg}$ balioen artean egotekotan gizabanakoak pre-hipertentsoak zirela kontsideratu zen eta balio horietatik gora $(>140 / 90 \mathrm{mmHg})$ hipertentsoak (10).

\section{Emaitzak}

Elgetako herriari zuzendutako zerbitzuen propagandari esker pertsona ugariren arreta lortu zen. Guztira, 79 pertsonak betetzen zituzten programan parte hartzeko irizpideak. Horiei, programaren berri nola izan zuten galdetzean, gehienek farmazialarien bitartez ezagutu zutela erantzun zuten (farmazialarien bitartez: \% 86; ahoz aho: \% 9; kartel edo egunkarien bitartez: \% 5).

Programan parte hartzeko irizpideak betetzen zituzten 79 pertsonetatik, 21ek uko egin zioten programan parte-hartzeari. Arrazoi nagusia denbora falta izan zen. Beste batzuk, analitikak maiztasunez egiten dituztela eta beren osasun-egoera kontrolatuta sentitzen dutenez kontrol gehiagoren beharrik ez zutela aitortu zuten. Bazeuden ezjakintasunean bizitzea nahiago zutenak. Guztira, 58 pertsonak erabaki zuten programan parte hartzea, 35 emakumek (\% 60) eta 23 gizonezkok (\% 40). 


\subsection{Findrisk testaren emaitzak}

Findrisk testean lortutako puntuetan oinarrituta, DM2a pairatzeko 3 arrisku taldetan sailkatu dira 58 pazienteak: 7 pertsona $(\% 12,1)$ arrisku baxukoak, 36 pertsona $(\% 62,1)$ arrisku ertainekoak eta 15 pertsona $(\% 25,8)$ arrisku altukoak.

Testaren arabera DM2a pairatzeko arrisku altua daukaten 15 pazienteek glukosaren proba egitea onartu zuten. Horietatik soilik batek izan zuen odoleko glukosa kontzentrazio altua (>110 mg/dl). Pertsona horri deribazio-gutuna eman zitzaion medikuarengana joan zedin.

\subsection{Aldatu ezin daitezkeen arrisku-faktoreak}

Programan parte hartu zuten gizabanakoen adinaren inguruan, gehien parte hartu zutenak nagusienak izan ziren (2. taula). Parte-hartzaileetatik 22 pertsonak $(\% 37,9)$ dituzte familiaaurrekariak (2. taula).

\begin{tabular}{|c|c|c|}
\hline Arrisku-faktorea & $\mathrm{n}$ & $\%$ \\
\hline \multicolumn{3}{|l|}{ Adina } \\
\hline$<45$ urte & 4 & 6,9 \\
\hline $45-54$ urte & 9 & 15,5 \\
\hline $55-64$ urte & 19 & 32,3 \\
\hline$>65$ urte & 26 & 44,8 \\
\hline \multicolumn{3}{|l|}{ Aurrekari familiarrak } \\
\hline Bai & 22 & 37,9 \\
\hline Ez & 36 & 62,1 \\
\hline
\end{tabular}

2. taula. Aldatu ezin daitezkeen arrisku-faktoreen emaitzak.

\subsection{Aldatu daitezkeen arrisku-faktoreak}

GMI balioen inguruan, partaideetatik 25ek arrisku ertaineko balioak azaldu arren, $18 \mathrm{k}$ balio osasuntsua $\left(<25 \mathrm{~kg} / \mathrm{m}^{2}\right)$ azaldu dute; eta gutxiengoak (15 pertsonak) arrisku altua $\left(>30 \mathrm{~kg} / \mathrm{m}^{2}\right)$. Gerriko perimetroaren inguruan, gizonezkoetan arrisku baxuko 2 pertsona,arrisku ertaineko 9 pertsona eta arrisku altuko 12 pertsona erregistratu dira. Emakumezkoetan, aldiz, arrisku baxuko 5 pertsona, arrisku ertaineko 4 pertsona eta arrisku altuko 26 pertsona erregistratu dira (3. taula).

Parte-hartzaileen bizimoduaren inguruko galderetan, \%51,7k beren aisialdian edo/eta lanean gutxienez egunero 30 minutuz ariketa fisikoa egiten dutela azaldu dute eta $\% 94,8 \mathrm{k}$ egunero fruta eta barazkia jaten dutela (3. taula).

Horrez gain, programan parte hartu duten gizabanakoen $\% 36,2 \mathrm{k}$ hipertentsiorako sendagaiak hartzen zituzten. Gainera, parte-hartzaileen $\% 89,7 \mathrm{k}$ ez du inoiz glukosa-maila alturik izan, ezta DM2 gaixotasunaren familia-aurrekaririk. Aldiz, 22 pertsonak (\% 37,9k) bi galderetako batean baietz esan du, eta gainerakoak, hots \% 5,2ak izan du glukosa-maila altua baita familia-aurrekariren bat ere ( 3 . taula). 
Ane Azpiazu, Ainhoa Oñatibia-Astibia, Amaia Garitano, Elena Elkoro, Nerea Osinalde

\begin{tabular}{|c|c|c|}
\hline Arrisku-faktorea & $\mathbf{n}$ & $\%$ \\
\hline \multicolumn{3}{|l|}{ GMI } \\
\hline$<25 \mathrm{~kg} / \mathrm{m}^{2}$ & 18 & 31,0 \\
\hline $25-30 \mathrm{~kg} / \mathrm{m}^{2}$ & 25 & 43,1 \\
\hline$>30 \mathrm{~kg} / \mathrm{m}^{2}$ & 15 & 25,9 \\
\hline \multicolumn{3}{|l|}{ Gerri-perimetroa (gizonezkoak/emakumezkoak) } \\
\hline$<94 \mathrm{~cm} /<84 \mathrm{~cm}$ & $2 / 5$ & $3,4 / 8,6$ \\
\hline $94-102 \mathrm{~cm} / 80-84 \mathrm{~cm}$ & $9 / 4$ & $15,5 / 6,9$ \\
\hline$>102 \mathrm{~cm} />84 \mathrm{~cm}$ & $12 / 26$ & $20,7 / 44,9$ \\
\hline \multicolumn{3}{|l|}{ Ariketa fisikoa } \\
\hline Bai & 30 & 51,7 \\
\hline Ez & 28 & 48,3 \\
\hline \multicolumn{3}{|l|}{ Fruta edo/eta barazkiak egunero jatea } \\
\hline Bai & 55 & 94,8 \\
\hline Ez & 3 & 5,2 \\
\hline \multicolumn{3}{|l|}{ Hipertentsiorako sendagaiak hartzen dituzte } \\
\hline Bai & 21 & 36,2 \\
\hline Ez & 37 & 63,8 \\
\hline \multicolumn{3}{|l|}{ Glukosa-maila altuak } \\
\hline Bai & 6 & 10,3 \\
\hline Ez & 52 & 89,7 \\
\hline \multicolumn{3}{|l|}{ Aurrekari familiarrak } \\
\hline Bai & 22 & 37,9 \\
\hline Ez & 36 & 62,1 \\
\hline Aurrekari familiarrak + glukosa-maila altuak & 3 & 5,2 \\
\hline
\end{tabular}

3. taula. Aldatu daitezkeen arrisku-faktoreen emaitzak.

\subsection{Presio arteriala}

HTArako medikaziorik hartzenez duten 37 parte-hartzaileetatik $15(\% 40,5)$ pre-hipertentso edo hipertentso bezala sailkatu dira (1. irudia, horiz eta gorriz, hurrenez hurren). Gainerakoak tentsiomaila egokiak dituzte (1. irudia, berdez).

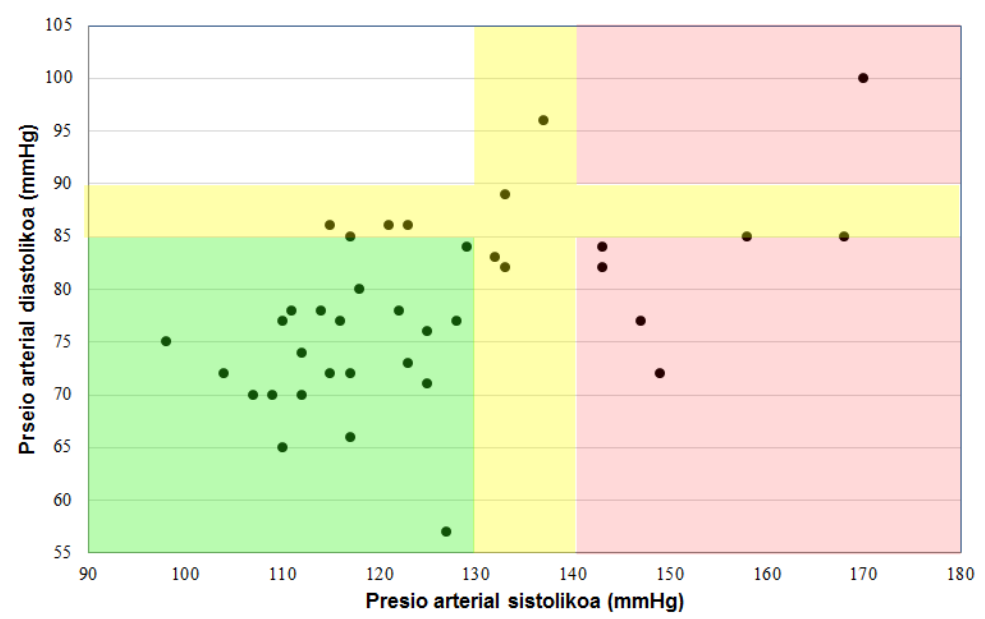

1. irudia. HTArako medikatuta ez dauden pertsonen sailkapena presio arteriala kontuan harturik. Kolore berdeak presio normala adierazten du, kolore horiak prehipertentsio egoera eta kolore gorriak hipertentsio egoera. 
Horrez gain, bildutako datuen arabera, HTArako medikamentua hartzen zuten 21 gizabanakoen artean gehiengoa, hots 12 paziente $(\% 57,1)$, ez da kontrolpean mantentzen (2.irudia).

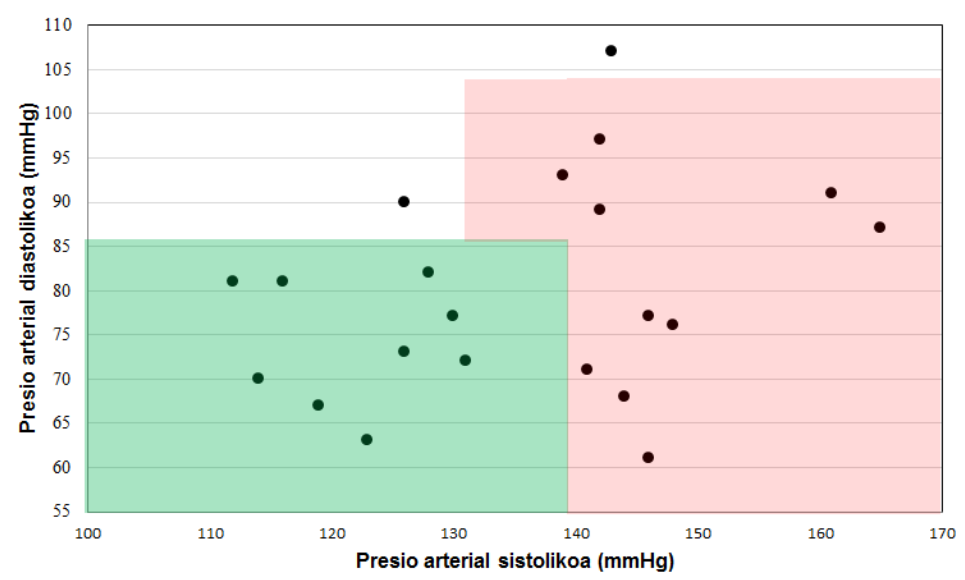

2. irudia. HTArako medikatuta dauden pertsonen sailkapena presio arteriala kontuan harturik. Berdez presioa kontrolpean dutenak, eta gorriz, presioa kontrolpean ez dutenak.

\section{Eztabaida eta ondorioak}

GSEk martxan jarritako "DM2a Pairatzeko Arriskua Antzemateko Programa" aditzera emateko metodorik eraginkorrena era aktiboa dela ikusi da, hau da, farmazialariok zuzenean pazienteei programa aurkeztea. Hala ere, aipatu behar da bakar batzuek programaren berri kartelen eta egunkarien bidez izan dutela, eta, horien artean gehienak diabetikoak izan direla. Horrek erakusten du gaixotasuna pairatzen dutenengan kartel edo egunkari bidezko iragarkiek gaixotasuna pairatzen ez dutenengan baino eragin handiagoa daukatela.

Adinari dagokionez ikusi da DM2a pairatzeko arrisku gehien duten pertsonen artean arreta gehiago piztu duela programak. Hau ez da harritzekoa, farmazietara gehien joaten direnak adineko pertsonak baitira. Gaixotasuna pairatzeko aukera gehiago dutenen artean burutu da osasunheziketa. Beraz, prebentzioaren helburua gehien behar duten pertsonetan bete dela esan daiteke.

Diabetesa prebenitu egin daiteke eta hori onuragarria da osasunarentzat. Hala ere, bada jendea programan parte hartzeari uko egiten diona. Hori, jendea prebentzioak duen garrantziaz kontzientziaturik ez dagoelako izan liteke. Arazo horren konponbidean osasun publikoak partehartze garrantzitsua izan dezake, besteak beste gaixotasunak eragin ditzakeen ondorio larriak biztanleriari indar handiagoz helaraziz. Horrekin batera, gaixotasuna prebenitzea zein erraza den eta horrek ekar ditzakeen onurak azpimarratzea ere oso lagungarria izan liteke.

Elgetako biztanleriaren erdia (\% 49,6a) emakumeak dira (14), horrez gain,farmaziara batez ere emakumeak etortzen dira, sendagaiez gain umeen zaintzarako produktuak, jateko produktuak edo kosmetikoak erostera. Kontuan izanda programan parte hartu duten gehienak farmazialarioi esker egin dutela, ez da harritzekoa parte-hartzaile gehienak emakumezkoak izatea. Beraz, pentsa liteke, parte-hartzaileen \% 60 emakumeak izatearen arrazoia bezero motarekin dagoela erlazionaturik eta ez gaixotasunarekin edo zerbitzua eskaintzeko moduarekin.

Elgetako biztanleria osasun-arloan kontrolaturik egotearen seinaletzat har liteke 58 partaideetatik pertsona batek bakarrik gainditzea glukosa basalaren balioa. Elgeta herri txikia izanik, osasun-arloko profesionalen arteko harremana, hala nola pazienteenganako gertutasuna, ohi baino handiagoa da. Botikako lanean nabaritzen denarengatik, edozein gorabehera dagoenean, berehala jartzen da 
pazientea farmazialari edo medikuarekin harremanetan eta ahalik eta azkarren hartzen dira neurriak pazienteen osasunaren hobe beharrez.

DM2a genetikoki transmititzen den gaixotasuna izanik, espero zitekeen programak bereziki aurrekari familiarrak dituztenengan piztea interesa. Hala ere, programan lortutako datuen arabera behintzat, Elgetan faktore horrek ez du hainbesterako eraginik izan, parte-hartzaileen gutxiengoak (\%38k) baitzeuzkan familia-aurrekariak. Beste aukera bat da aurrekariak dituzten pertsonek jada DM2a pairatzea eta horrenbestez gure programan ezin partehartzea. Prebentzioak aurrekariak dituzten pertsonetan indar gehiago izatea garrantzitsuagoa da. Beraz, alde horretatik, programak hainbeste etekinik ez duela izan esan liteke, parte-hartzaile gehienak aurrekari gabeak izan direlako. Gainera, arrazoia edozein delarik ere (bai jada Elgetan gaixo dauden pertsona gehiegi daudelako edo bai gaixotasunari garrantzia ematen ez dioten gehiegi) DM2a pairatzeko aurrekariak azaltzen dituzten pertsonetan prebentzioa indartu behar dela ondoriozta daiteke.

GMI eta gerriko perimetroari dagokienez, ikusi da arazoa ez dagoela pisuarekin hain loturik, baizik eta abdomenean metatzen den gantz kantitatearekin. GMlari erreparatuz, parte-hartzaileen gehiengoak DM2a pairatzeko arrisku ertaina dauka, aldiz, gutxiengoak arrisku altua. Gerriko perimetroaren emaitzak kontuan hartuz, aldiz, emakume eta gizonezkoen artean aldea egonda ere, paziente gehienek DM2a pairatzeko arrisku altua daukate. Emaitza horiek kontuan izanda pentsa liteke biztanleriak sinesmen okerrak dituela zenbait osasun-kontzepturen inguruan. Norbanakoen pisuaren eta osasun-egoeraren artean dagoen harremana ondo finkatuta dagoela dirudi.

Aipatu den bezala, DM2aren prebentzioan eguneroko bizitzan mantentzen diren ohiturek eragin handia dute. Jaso diren emaitzen arabera ondoriozta daiteke programan parte hartu duten Elgetako biztanleen ohitura higieniko-dietetikoak egokiak direla. 58 pertsonatik 55ek egunero jaten dute fruta, barazkiak edo biak. Gainera, programan parte hartu duten pazienteen erdiak egunero ariketa fisikoa egiten du eta hori seinale ona da. Hala ere, ariketak DM2a prebenitzeko duen garrantzia kontuan hartuta, herritarren artean gehiago sustatu beharreko gauza dela ondorioztatu da. Garrantzitsua da pertsonaren egoera fisikoa ezagutzea eta gehien komeni zaion ariketa gomendatzea.

DM2a pairatzeko arriskuan pisu gehien duten faktoreak, hots glukosa-maila basala eta familiaaurrekariak, batera aztertuta datu positiboak lortu dira. Programan parte hartu duten pazienteen erdiek baino gehiagok ez dute DM2aren aurrekaririk familian eta ez dute inoiz glukosa basala altu izan. Bakarrik 3 pertsonak erantzun diete baiezkoa bi faktoreei. Beraz, Elgetako biztanleriak ez du gaixotasuna izan duten familia-aurrekari asko eta eurei ere ez zaizkie glukosa-maila altuak detektatu.

Findrisk testean lortutako puntuaketan oinarrituta, Elgetako biztanleriaren gehiengoak datozen hamar urteetan DM2a pairatzeko arrisku ertaina duela ondorioztatu dezakegu. Datu hau, Espainia mailan egin direnikerketekin alderatu daiteke (15) eta farmazialariak osasun-heziketan duen garrantzia goraipatzen du.

Tentsio arterialari dagokionez, hipertentsiorako medikazioa hartzen duten zein medikaziorik gabe dauden taldeetan, bietan, jende kopuru handiena osasunarentzat onargarria den tartean dagoela ikusi da. Hala ere, nabarmentzekoa da medikazioa hartzen dauden pertsonen artean gaizki kontrolaturik dagoen jende kopurua HTArako medikaturik ez dauden eta hipertentsio balioen artean dagoen jende kopurua baino handiagoa dela.

Aurreko guztia laburbilduz, esan behar da programa batez ere 40 urtetik gorakoentzat egonik Elgeta herri aproposa izan dela burutzeko, bertako biztanleriaren \%57,3 40 urtetik gorakoa baita. Elgetako biztanleria orokorrean osasuntsu mantentzen dela ondorioztatu da; hala ere, arlo batzuetan hainbat gabezia antzeman dira. GMlaren datuak onak izan arren gerriko perimetroarenak ez dira hain onak izan. Horrek biztanleen osasun-kontzeptuan akatsa dagoela adierazten du, pisu egokia edukitzeak ez baitu osasuna bermatzen. Ariketa fisikoari dagokionez, herritarren artean gehiago 
sustatu behar dela ondorioztatu da. Horrez gain HTArako medikatuak dauden gehienek tentsio arteriala gaizki kontrolatuta daukatela behatu da. Pentsatzekoa da ariketa fisiko ezak HTAren kontrol ezegokian eragina duela; baina datuen arabera, tentsio arterial sistolikoa gaizki kontrolaturik duten 10 pertsonetatik 8k egunero ariketa fisikoa egiten dute, beraz, ez dute harremanik. Argi dago parametro horiek (gerriko perimetroa, eguneroko ariketa fisikoa eta HTA) hobetu ahal izateko eta pazienteek beldurra galtzeko osasun-heziketa indartu behar dela. Aurreragoko ikerketentzat interesgarria izango litzateke elikaduraren inguruan galdeketa zehatzago bat egitea, horrela, farmaziatik aholku pertsonalizatuagoak emateko aukera egongo litzatekeelako.

Amaitzeko, gogoratu beharra dago DM2a pairatzeko arriskua antzemateko programa Gipuzkoako hainbat farmaziatan gauzatu dela. Zehazki Elgetako farmazian garatutako programak ekainaren amaiera arte iraun du eta ondorioz oraindik ezin izan dira lortutako emaitzak Gipuzkoa osoan lortutako emaitzekin konparatu. Etorkizunean Gipuzkoako farmazia ezberdinetan lortutako emaitzak partekatu eta landuko dira, Gipuzkoako biztanleriak DM2a pairatzeko duen arriskua eta oro har duen osasun-egoera zein den hobeto ezagutzeko.

\section{Eskerrak eta oharrak}

Lan hau Farmazia Graduaren amaierako lanetik eratorria da.

\section{Erreferentzia bibliografikoak}

1. García Soidán FJ, Malo García F, Muiño López-Álvarez X, Martínez Vidal A, Plana Pintos R, Modroño Freire MJ, Gestoso Lamazares T, Paramio Castedo F, Conde Guede L, López Pereiro O. Diabetes Mellitus tipo 2 [Internet]. Barcelona: Elsevier; 2017 [Kontsulta 2018-02-20]. 32 or. Eskuragarri: http://www.fisterra.com/guias-clinicas/diabetes-mellitus-tipo-2/

2. Bluestone JA, Herold K, Eisenbarth G. Genetics, pathogenesis and clinical interventions in type 1 diabetes. Nature. 2010; 464(7293): 1293-1300.

3. Donath MY, Shoelson SE. Type 2 diabetes as an inflammatory disease. Nat Rev Immunol. 2011; 11: 98-107.

4. Brown J, Alwan NA, West J, Brown S, McKinlay CJD, Farrar D, Crowther CA. Lifestyle interventions for the treatment of women with gestational diabetes. Cochrane Database of Systematic Reviews 2017, Issue 5. Art. No.: CD011970. DOI:

10.1002/14651858.CD011970.pub2.

5. Nomiyama T, Yanase T. [Secondary diabetes]. Nihon Rinsho. 2015; 73(12): 2008-12.

6. Colegio Oficial de Farmacéuticos de Gipuzkoa. 119 farmacias guipuzcoanas participanen el programa para la deteccion de ciudadanos en el riesgo de padecer diabetes tipo 2. Botika XXI. 2017; 39:6.

7. Fornos Pérez JA. Guía práctica de atención farmacéutica al paciente diabético. Madrid: Sociedad Española de Farmacia Comunitaria; 2012. 192 or.

8. McFarlaneSI, BakrisGL. Diabetes and hypertension: evaluation and management. New York : Humana Press; 2012. 190 or.

9. Diabetes Prevention Program Research Group, Knowler WC, Fowler SE, Hamman RF, Christophi CA, Hoffman HJ, Brenneman AT, Brown-Friday JO, Goldberg R, Venditti E, Nathan DM. 10-year follow-up of diabetes incidence and weight loss in the Diabetes Prevention 
Ane Azpiazu, Ainhoa Oñatibia-Astibia, Amaia Garitano, Elena Elkoro, Nerea Osinalde

Program Outcomes Study. Lancet. 2009;374(9702):1677-86.

10. Moliner de la Puente JR, Castiñeira Pérez C, Domínguez Sardiña M, Teresa Rios Rey M, Chayán Zas L, Gil Teijeiro J, González Paradela C, Leiro Manso A, Marín Sánchez ML. Hipertensión arterial[Internet]. Barcelona: Elsevier; 2017 [Kontsulta 2018-02-20]. 32 or. Eskuragarri: http://www.fisterra.com/guias-clinicas/hipertension-arterial/

11. Guía de actualización en diabetes [Internet]. Sabadell: Fundación redGDPS;2016 [Kontsulta 2017-05-06].131 or. Eskuragarri: http://redgdps.org/gestor/upload/GUIA2016/CAP1.pdf

12. Sami W, Ansari T, Butt NS, Hamid MRA. Effect of diet on type 2 diabetes mellitus: A review. Int J Health Sci (Qassim). 2017; 11(2):65-71.

13. Franks PW, McCarthy MI. Exposing the exposures responsible for type 2 diabetes and obesity. Science. 2016; 354(6308):69-73.

14. Demografia Elgeta. Foro ciudad;2017 [Kontsulta 2018-03-20]. Eskuragarri: https://www.forociudad.com/guipuzcoa/elgeta/habitantes.html.

15. Fornos JA, Andrés NF, Andrés JC, Acuña A, Costas D, Mera R. Detección de pacientes con riesgo de desarrollar diabetes en farmacias comunitarias de Pontevedra. Farmacéuticos Comunitarios. 2013 Dec 19; 5(4):141-146. 